\author{
Brief article
}

\title{
Word order and information status in child language
}

\author{
Bhuvana Narasimhan *, Christine Dimroth \\ Max Planck Institute for Psycholinguistics, PB 310, 6500 AH Nijmegen, The Netherlands
}

Received 10 February 2007; revised 11 July 2007; accepted 20 July 2007

\begin{abstract}
In expressing rich, multi-dimensional thought in language, speakers are influenced by a range of factors that influence the ordering of utterance constituents. A fundamental principle that guides constituent ordering in adults has to do with information status, the accessibility of referents in discourse. Typically, adults order previously mentioned referents ("old" or accessible information) first, before they introduce referents that have not yet been mentioned in the discourse ("new" or inaccessible information) at both sentential and phrasal levels. Here we ask whether a similar principle influences ordering patterns at the phrasal level in children who are in the early stages of combining words productively. Prior research shows that when conveying semantic relations, children reproduce language-specific ordering patterns in the input, suggesting that they do not have a bias for any particular order to describe "who did what to whom". But our findings show that when they label "old" versus "new" referents, 3- to 5-year-old children prefer an ordering pattern opposite to that of adults (Study 1). Children's ordering preference is not derived from input patterns, as "old-before-new" is also the preferred order in caregivers' speech directed to young children (Study 2). Our findings demonstrate that a key principle governing ordering preferences in adults does not originate in early childhood, but develops: from new-to-old to old-to-new.
\end{abstract}

(c) 2007 Elsevier B.V. All rights reserved.

Keywords: Word order; Information status; Language acquisition; German

\footnotetext{
${ }^{*}$ Corresponding author. Tel.: +31 (0)24 3521231.

E-mail address: bhuvana@mpi.nl (B. Narasimhan).
} 


\section{Introduction}

Across many languages, adults prefer to order "old" information before "new" information (Levelt, 1989; Wundt, 1900), and such a preference has been proposed as a possible linguistic universal (Clark \& Clark, 1978). The "old-before-new" ordering preference is posited to have information processing value for adult speakers since prior mention of a referent facilitates earlier production of the accessible information (Bock \& Irwin, 1980; Ferreira \& Yoshita, 2003). If similar considerations influence how children linearize their thinking for the purposes of speaking, we would predict that accessibility should lead to an "old-before-new" ordering preference in children as well. In addition, the "old-before-new" ordering in adults' usage patterns constitutes input to children learning language, and may also lead to an early preference for an old-before-new ordering in children if they are sensitive to the correspondence between linear order and information status in the ambient language.

However the findings from child language are contradictory, suggesting a "newbefore-old preference" (Bates, 1976; MacWhinney, 1982), an "old-before-new" preference (Menyuk, 1969), or no significant ordering preference at all (MacWhinney \& Bates, 1978). And deaf children, who are not exposed early to a conventional sign language, invent gesture systems that use consistent order for particular semantic elements but are claimed to show no particular ordering tendency based on an "old" versus "new" distinction (Goldin-Meadow \& Mylander, 1984). Overall, there appears to be little evidence that young children have a consistent ordering preference based on information status.

But the contradictory findings in child language may have other explanations having to do with the influence of confounding factors at the sentential level. In many cases, the use of the terms "old" and "new" conflates the notion of accessibility with the "topic-comment" distinction. Accessibility has to do with how available a referent is in the minds of speakers and hearers in a particular communicative context. Several factors influence accessibility, including prior mention of referents in the discourse, as well as their prototypicality (Kelly, Bock, \& Keil, 1986) and imageability (Bock \& Warren, 1985), among others. On the other hand, the term "topic" refers to what the utterance is about while "comment" refers to what speakers predicate of the topic. Although the topic is typically accessible to the speaker and hearer and the comment is often inaccessible and new, in principle, the two distinctions are orthogonal (von von von von Stutterheim \& Klein, 2002). In example (1), she is the topic and herself belongs to the comment, but both expressions denote a referent that has been mentioned before (cf. Reinhart, 1982):

\section{Who did Anita see in the photograph? She saw herself.}

In addition to the topic-comment distinction, accessibility may also interact with other relational asymmetries, such as agent-patient or subject-object that also influence word order at the sentence level. As a consequence, researchers have experimentally investigated how accessibility influences linear order at the phrasal level: in 
adults' production of conjoined noun phrases, where the conjoined elements share the same semantic and grammatical role and are symmetrical with respect to the topic-comment dimension. For instance, even though both vodka and orange juice in the answer to the question (in 2a) are part of the comment, adults prefer the order vodka and orange juice, when vodka is mentioned in the preceding context (Bock, 1977):

2a. A man went into a bar and ordered a screwdriver, but the bartender said he was out of vodka. What difference does it make?

b. A screwdriver is made of vodka and orange juice.

In our study, we adapt this methodological procedure in order to investigate the influence of the accessibility of referents on order of mention at the phrasal level in young children.

The study draws on elicited production data from (a) children and adults interacting with another adult and (b) caregivers interacting with their children. For reasons of ecological validity, a referential communication task involving picture-matching was employed in order to elicit descriptions of objects in contexts that are interactive and yet controlled (Yule, 1997). In our study, the use of conjoined noun phrases allows us to control for the topic-comment distinction as well as asymmetries at other levels, such as agent-patient or subject-object. The accessibility of referents in our study is determined on the basis of prior mention of a referent in a specific discourse context ("old" information) versus the first introduction of a referent ("new" information). We also controlled for the role of multiple variables known to influence order of mention, including the weight and frequency of referring expressions, the spatial relationship between referents, and their animacy, among others (Arnold, Wasow, Losongco, \& Grinstorm, 2000; Clark \& Chase, 1972; Cooper \& Ross, 1975; Pinker \& Birdsong, 1979; Prat-Sala, Shillcock, \& Sorace, 2000; Wright, Hay, \& Bent, 2005;).

\section{Study 1}

\subsection{Participants}

Participants were 16 3-year-olds (mean age 3;7 years) and 16 5-year-olds (mean age 5;5 years) acquiring German recruited through local kindergartens (Kleve, Germany). Additionally, 24 adult native speakers of German acted as controls.

\subsection{Materials}

The stimulus materials consisted of 24 inanimate objects. The objects were selected based on parental reports of early and frequent use of the labels for these objects by children acquiring German (Grimm \& Doil, 2000). In order to avoid collocations where the word order is fixed (e.g. bread and butter), the 24 objects were 
grouped into 12 pairs such that combinations were unlikely to occur in participants' everyday experience, e.g. "egg" and "bed" (Table 1). Object pairs were also matched on the number of syllables, grammatical gender, and frequency of use of the corresponding object labels. Three warm-up items and 13 filler events were also included. Importantly, filler events included object pairs that were both new so that the participants could not presuppose that the "old" referent would always be one of the objects in the trials where two objects are shown to the participant. A set of photos of each of the objects was also produced. The stimulus items were randomized and organized into two orders ("back" and "forward"). Within each age group, the order of stimulus presentation was counterbalanced.

\subsection{Procedure}

Participants were first shown an object (e.g. an egg) in a transparent, round container. An experimenter who could not see the container asked the question: was ist da drin? "what's in there?" in response to which the participant described the contents of the container. The experimenter repeated the participant's object description and identified the picture matching the object. The participant was then shown two objects in a container, one of which consisted of the object that had been described before (e.g. an egg and a bed), and asked again to describe its contents to help the experimenter find the matching pictures. In order to avoid showing the participant the two objects in a fixed spatial relation to each other, the container was rotated during the presentation, so that the two objects were viewed from different spatial perspectives. To control for any effects of the salience of individual objects, the object that was initially introduced on its own (the "old" referent) was counterbalanced within each age group (object-1 presented first versus object-2 presented first). The entire testing session was audiotaped.

Crucially, in our study, the use of the question was ist da drin? "what's in there?" provides discourse encouragement for a response in which both object labels belong

Table 1

Labels for object pairs used as stimuli

\begin{tabular}{llll}
\hline Object label 1 & English gloss & Object label 2 & English gloss \\
\hline Apfel & 'apple' & Löffel & 'spoon' \\
Ei & 'egg' & Bett & 'bed' \\
Brille & 'glasses' & Hose & 'trousers' \\
Buch & 'book' & Haus & 'house' \\
Traktor & 'tractor' & Eimer & 'bucket' \\
Stuhl & 'chair' & Stein & 'stone' \\
Käse & 'cheese' & Schlüssel & 'key' \\
Ball & 'ball' & Schuh & 'shoe' \\
Tasse & 'cup' & Socke & 'sock' \\
Baum & 'tree' & Tisch & 'table', \\
Mütze & 'cap' & Blume & 'flower' \\
Auto & 'car' & Messer & 'knife' \\
\hline
\end{tabular}


to the "comment" part of the utterance. That is, the two object labels (e.g. Ei und Bett 'egg and bed' or Bett und Ei 'bed and egg'), are similar in providing information about the contents of the container referred to in the preceding question. Both labels are also similar in sharing the same grammatical and semantic role. Thus, the primary difference between the two object labels lies in their accessibility: whether or not their referents have been mentioned before.

\subsection{Data treatment}

The first spontaneous description of each object pair was transcribed and 68 responses were excluded from a total of 672 responses. Scoreable responses included those in which both object labels were produced. If labels other than the target labels were used, they were included if they were possible descriptions of the object (e.g. Strumpf 'stocking' instead of Socke 'sock'). Responses were excluded if they consisted of only one object label, the speaker vacillated between two orders or object labels, or the object label did not accurately describe the object. We also excluded responses if the experimenter erroneously repeated the participant's description of the first-introduced object three or more times, as multiple repetitions may unduly increase the "oldness" of the first-introduced referent.

The remaining, scoreable, responses were annotated for order of mention ("new-before-old" or "old-before-new"). As the weight of the object description may influence ordering strategies such that longer noun phrases are preferred in final position ("Panini's Law"), we also coded responses for the number of syllables in the noun phrase used to describe the object (e.g. kleines Bett was "heavier" than Bett). This yielded 3 categories of responses: "heavy phrase in first position", "heavy phrase in second position" and "no difference in the relative weights of the two object labels". Further, although adults and children overwhelmingly used the conjunction und 'and', a small proportion of responses had no overt conjunction (3\%), or involved the use of mit 'with' $(4 \%)$. These responses were annotated as "und", "null", and "mit", respectively. Further, the use of "local" markings (Hickmann, Hendriks, Roland, \& Liang, 1996), such as (in)definite determiners, to encode "new" versus "old" referents may influence word order choice. Determiners can only play a role in signaling accessibility if different types of determiners are used for each of the conjoined elements. So we also coded our data for determiner use in the responses based on whether or not determiners were used contrastively for new versus old referents. This yielded two categories: "same marking" (e.g. no determiner used with either noun phrase, or a (in)definite determiner used with both noun phrases) and "different marking" (e.g. a combination of definite and indefinite determiner, a (in)definite determiner with no determiner at all, etc.). Finally, as fluency may provide an indication as to whether children's ordering patterns are stable or constitute "groping patterns" (Braine, 1976), responses were also annotated for whether the two object labels were uttered in one intonation contour with no preceding or intervening hesitations or pauses ("fluent"), or whether they were marked by pauses or distinct intonation contours ("non-fluent"). 
Intercoder reliability was established between two research assistants (not blind to the hypotheses of the study) on $20 \%$ of all responses using Cohen's kappa. The primary coder coded all the responses for response type, number of repetitions, weight, conjunction type, determiner use, and fluency. The second coder independently coded $20 \%$ of the responses selected randomly. Cohen's kappa was 1.00 for response type, weight and conjunction, 0.96 for repetition and determiner, and 0.89 for fluency.

\subsection{Analysis and results}

We ran a mixed-effect logistic regression model (Baayen, in press), using contrast coding for the fixed effects, with order of mention ("new-before-old" and "oldbefore-new") as the outcome variable. There were two random effect factors, participant and item. The model had as predictor variable, age (3-year-olds, 5-year-olds, and adults). As our study involved a free-response task in order to encourage natural communication between interlocutors, both children and adults exhibited variation in their responses from the canonical target response, $X$ und $Y^{\text {" }} \mathrm{X}$ and $\mathrm{Y}$ ", producing object labels of differing lengths (or "weights"), different conjunction and determiner types, and utterances varying in fluency. We therefore entered, as control variables, weight ("heavy-first", "heavy-last", "no weight difference"), conjunction (mit 'with', und 'and', and "null"), determiner ("same marking", "different marking"), and fluency ("fluent", "non-fluent").

Fig. 1 shows the mean proportion of responses with the "new-before-old" versus "old-before-new" order for each age group. ${ }^{1}$

Our results show that, in keeping with prior research, adults prefer to order "old" information before "new" information $(\beta=1.15, Z$ value $=4.22, p<.001)$. Children also have a consistent ordering preference that is significantly different from chance. Keeping participant and item as random effects with only an intercept, we get an intercept significantly different from zero for 3-year-olds $(\beta=-0.63, Z$ value $=-2.86$, $p<.01)$ and 5-year-olds $(\beta=-0.64, Z$ value $=-2.29, p<.05)$. But children's preferences go in the opposite direction to that of adults (see Table 2). Children prefer to order "new" before "old" information significantly more often than adults (3-yearolds: $\beta=-1.80, \quad Z$ value $=-4.25, \quad p<.001$, odds ratio $=0.17 ; 5$-year-olds: $\beta=-2.02, Z$ value $=-5.12, p<.001$, odds ratio $=0.13) .{ }^{2}($ The standard deviation for the participant random effect was 0.94.) The highest posterior density (HPD) intervals for these model coefficients do not cross zero (see Table 2), suggesting significant differences between the child and adult groups. An interaction of age by fluency

\footnotetext{
${ }^{1}$ The mean proportions and standard errors (calculated over by-subject proportions) displayed in Fig. 1 (and Fig. 2 in Section 3.3) are not used in our logistic regression analysis. See Table 2 for 95\% HPD (highest posterior density) intervals for the model coefficients calculated on 5000 Markov Chain Monte Carlo samples from the posterior distributions of the parameters (see ch. 7, Baayen, in press). HPD intervals show the range of values the coefficients are likely to have $95 \%$ of the time.

${ }^{2}$ As the variance for the item random effect was extremely small $(0.0000000005)$ and a likelihood ratio test showed it did not contribute to the model, we removed item as predictor from the model.
} 


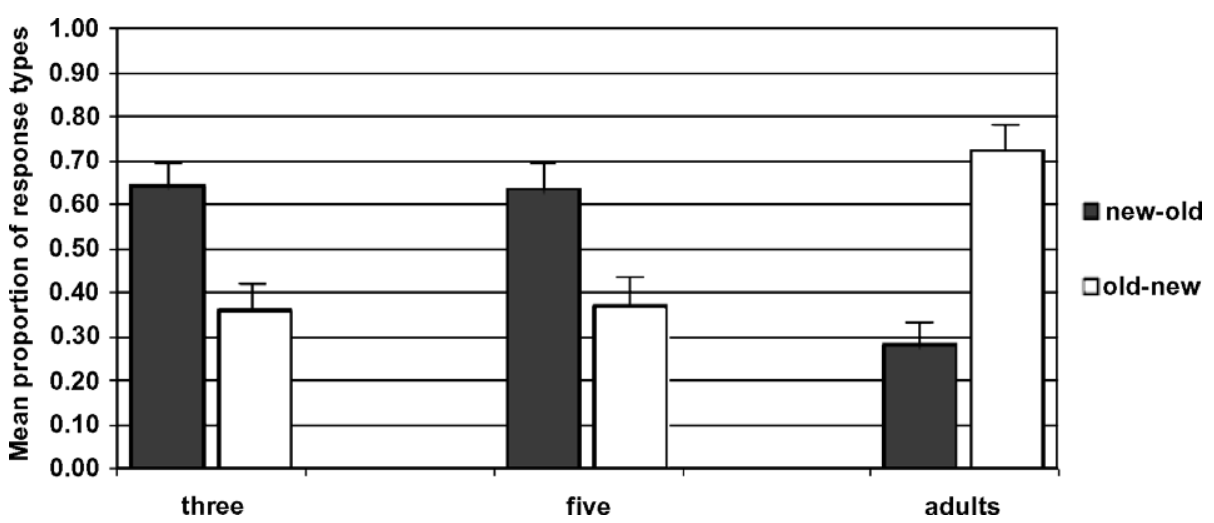

Fig. 1. "New-old" versus "old-new" responses in 3-year-olds, 5-year-olds, and adults (error bar = standard error).

Table 2

Effects of age and fluency on the choice of "old-new" versus "new-old" order in 3-year-olds, 5-year-olds, and adults

\begin{tabular}{|c|c|c|c|c|c|c|c|}
\hline & \multirow[t]{2}{*}{ Estimate } & \multicolumn{2}{|c|}{ HPD intervals } & \multirow[t]{2}{*}{ Std. error } & \multirow[t]{2}{*}{$Z$ value } & \multirow[t]{2}{*}{$p$ value } & \\
\hline & & Lower & Upper & & & & \\
\hline (Intercept) & 1.15 & 0.65 & 1.72 & 0.25 & 4.62 & $p<.001$ & $* * *$ \\
\hline Age: three & -1.80 & -2.69 & -0.90 & 0.42 & -4.25 & $p<.001$ & $* * *$ \\
\hline Age: five & -2.02 & -2.82 & -1.15 & 0.39 & -5.12 & $p<.001$ & $* * *$ \\
\hline Fluency: non-fluent & -0.38 & -1.37 & 0.53 & 0.46 & -0.83 & 0.4091 & \\
\hline Age: three $*$ fluency: non-fluent & 0.32 & -1.02 & 1.41 & 0.59 & 0.55 & 0.5844 & \\
\hline Age: five $*$ fluency: non-fluent & 1.37 & 0.13 & 2.69 & 0.63 & 2.17 & 0.0299 & $*$ \\
\hline
\end{tabular}

revealed one significant coefficient that however did not survive a Bonferroni correction or a likelihood ratio test. There were no other interactions of age with any of the other control variables. As we can see from the minimal difference in the values for the estimated coefficients and standard deviations for 3-year-olds versus 5-yearolds in Table 2, there is no development in preference for the "new-before-old" order even by age five, demonstrating that children's non-adult-like ordering bias persists well beyond the early stages of productive word combination. ${ }^{3}$ We evaluated the goodness-of-fit of our model using the $C$ statistic (an index of concordance between the predicted probability and the observed response) and Somers' $D_{x y}$ (a rank correlation between predicted probabilities and observed responses) (Baayen, in press), and obtained values of 0.823 for $C$ and 0.646 for Somers' $D_{x y}$.

\footnotetext{
${ }^{3}$ In order to examine whether children switch their ordering preference to "old-before-new" when the activation status of the "old" item is increased, we looked at excluded responses where the experimenter had named the given item three times or more. There were only 10 such responses $(5$ from children and 5 from adults), but the patterns do not change. Children produced the "old-before-new" order 1/5 times and the adults produced the "old-before-new" $5 / 5$ times.
} 


\subsection{Discussion}

Our first study shows that newness of information influences ordering preferences in different ways in children and adults. Adults prefer to label first a referent made relatively more accessible by prior mention versus a newly introduced referent, whereas children have the opposite preference. Further, since children's ordering preference continues to go in the opposite direction to that of adults even at age five, ordering patterns in adult language also do not appear to be playing a significant role in shaping children's ordering preferences.

But it is possible that word order in the speech of adults directed to children ("child-directed speech") is not always the same as in the speech of adults addressing other adults. It is well known that child-directed speech in some cultures is characterized by a number of features that differ from speech directed to adults, e.g. in the use of exaggerated intonation and stress, relatively restricted vocabulary, and more reference to the here and now (Gleason \& Weintraub, 1978; O'Grady, 1997). It is possible that in talking to their children versus adults, caregivers overcome their processing preference and foreground new referents by introducing them in the first position, before mentioning referents that have already been described before. Given children's sensitivity to patterns in the input (Tomasello, 2003), it is possible that children's "new-before-old" preference is influenced by a similar preference in child-directed speech. Therefore we next investigated whether typical characteristics of the input to children are responsible for the "new-before-old" ordering preference we found in children.

\section{Study 2}

\subsection{Participants}

Twenty-four German-speaking adult caregivers (of children aged 2;5 to 6;1) participated in a modified version of the procedure described in our first study.

\subsection{Procedure}

Participants were invited to play a game that involved helping their children with a picture-matching task. As in study 1 , singleton objects were presented to (and labeled by) the caregiver immediately prior to each test trial. During the test trial, caregivers were shown pairs of objects in a container and asked to provide object descriptions to the child, rather than an adult experimenter. Each child was provided with a set of object pictures arranged in groups of three, and asked to point to the object(s) described by their caregiver. In other respects, the procedure was the same as that employed in our first study. The outcome variable was the order of object labels provided in the caregivers' object descriptions addressed to the child. 


\subsection{Analysis and results}

Responses were included based on the criteria outlined in Study 1. The scoreable responses (272 out of 288 responses) were annotated for order of mention ("newbefore-old" or "old-before-new"), repetition, weight, conjunction, determiner, and fluency (see Section 2.4 for details). Intercoder reliability tests showed no disagreement between the primary rater who coded all the responses, and a second rater who coded $10 \%$ of the responses (Cohen's kappa $=1.00$ for all coding categories).

As before, we ran a mixed-effect logistic regression model with order of mention ("new-before-old" and "old-before-new") as the outcome variable. There were two random effect factors, participant and item. Control variables included conjunction type, weight, and fluency. The variable "determiner" was not included as a control variable since caregivers rarely showed variation in the types of determiners that they used in their responses.

Fig. 2 shows the mean proportion of caregivers' responses that consisted of object labels in the "new-before-old" order versus the "old-before-new" order.

There were no main effects of conjunction type, weight, and fluency. Keeping participant and item as random effects with only an intercept, we get an intercept significantly different from zero $(\beta=1.12, Z$ value $=4.98, p<.001,95 \%$ HPD interval is $0.81-1.16$ ). (The standard deviation for the participant random effect was 0.84 , and for the item random effect, it was 0.0000224). Goodness-of-fit measures for the model were calculated: we obtained a value of 0.78 for the $C$ index of concordance and 0.56 for Somers' $D_{x y}$.

\subsection{Discussion}

In addressing children, caregivers, like the adults in Study 1, prefer the "old-before-new" order at levels significantly different from chance. The

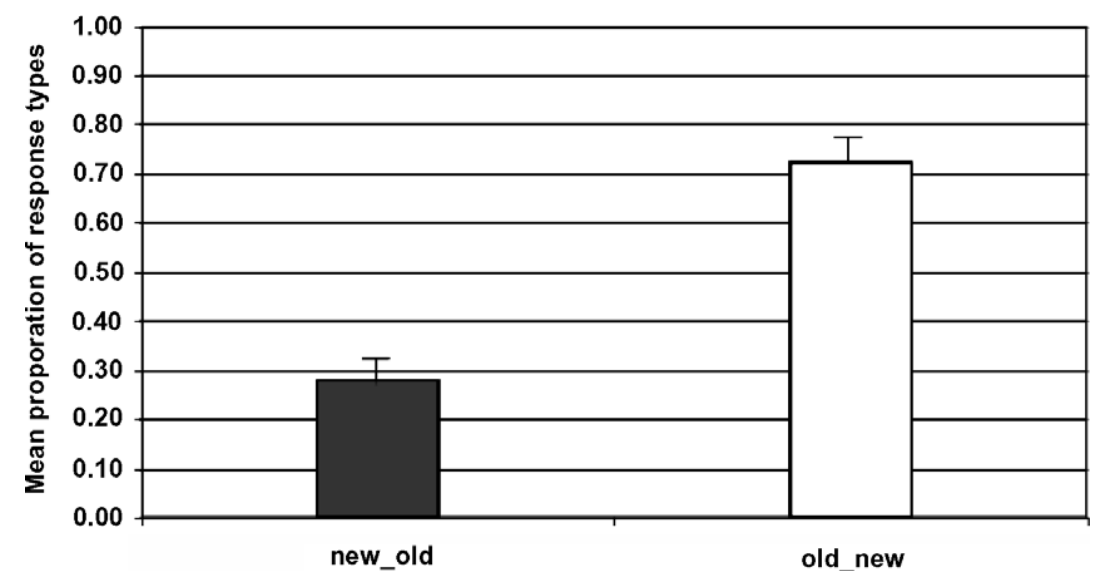

Fig. 2. "New-old" versus "old-new" responses in child-directed speech (error bar = standard error). 
"old-before-new" preference in child-directed speech may not be confined to the phrasal level - repeated words are less likely to be utterance-final than new words in the speech of English-speaking mothers addressing their 14-month-old infants (Fisher \& Tokura, 1995). Our results demonstrate that children's preference for the "new-before-old" order does not reflect the preferred order in the speech produced by caregivers in the same types of communicative contexts.

\section{General discussion}

The findings from our two studies show that in the early stages of productively combining words, children's ordering patterns are influenced by a distinction in the accessibility of referents, "new" versus "old", that influences adults' ordering preferences as well. But newness influences linear order in children differently than in adults, with children showing a robust preference for the non-adult-like "newbefore-old" order. Our findings shed light on previous findings showing a "newbefore-old" ordering preference at the sentential level (Baker \& Greenfield, 1988; Bates, 1976; MacWhinney, 1985) by demonstrating that prior mention in the discourse is not only sufficient to influence children's ordering preferences at the phrasal level, independently of sentence-level factors such as topicality, agentivity, or subjecthood, but continues to influence children's non-adult-like ordering preferences well beyond the early period of multi-word utterances. Further research is required to determine whether prior mention influences children's ordering patterns at the sentential level as well when potentially confounding factors are controlled for. It would also be interesting to examine when a shift in preference to the "old-beforenew" order occurs, especially given prior work showing changes at the age of nine in children's interpretation of linguistic cues (e.g. stress) to topic-comment distinctions in isolated sentences (MacWhinney \& Price, 1980) and in their strategies in pronoun use to indicate the discourse topic in narratives (Karmiloff-Smith, 1986).

Our findings are surprising given that the "old-before-new" order has been shown to have information processing value for speakers owing to the increased availability of previously mentioned referents for early positioning during speech production. Children's preference for the "new-before-old" order demonstrates that the processing considerations influencing linear ordering in adults do not play the same role during the early stages of children's productive word combinations, but develop during later childhood.

Our findings are also unexpected in light of prior research showing children's early conformity to ordering patterns in the input when conveying semantic distinctions, "who does what to whom". The rarity of deviant word orders in child language to label notions such as "agent" or "patient" (Akhtar \& Tomasello, 1997) suggests the powerful role of language-specific ordering patterns, and raises the issue of the nature of children's biases that may influence their early use of language. Our study shows that children's "new-before-old" ordering preference may reflect a cognitive or communicative bias in the child rather than patterns in the ambient language. 
Interestingly, this bias goes in the opposite direction to the putatively universal "oldbefore-new" ordering principle.

If neither the accessibility of a referent for the speaker nor input patterns can account for the difference between the ordering patterns in children versus adults, what other factors might play a role? Perhaps the "old-before-new" preference in adults is (also) influenced by factors such as the temporal order in which events occur, e.g. the order in which they encounter objects in our study. Alternatively, habitual exposure to, and use of, a topic-before-comment pattern at the sentential level might influence adults' "old-before-new" preference at the phrasal level owing to the frequent association of topics (what an utterance is about) with "old" referents (what is accessible to the hearer and speaker). Additionally, speakers' sensitivity to the knowledge state of the hearer may influence how they tailor their utterances. Children's non-adult-like ordering patterns might arise from their insensitivity to any or all of these potentially influential factors. But if this were the case, children's ordering patterns should be randomly distributed between "old-new" and "new-old" orders until they develop the requisite sensitivities.

Children's systematic "new-before-old" ordering preference requires a different explanation - one that may be related to their selection preferences at an early age. Children's ordering of "new" referents first may reflect a propensity to give priority to novel or changing elements in a situation for the purposes of speaking, a tendency that may be also reflected in which aspects of a situation they select for encoding (Bates, 1976). Early on, children tend to encode the novel or changing aspects of a situation in their single-word utterances, and even when they are capable of producing longer utterances at the two-word stage, prefer to omit elements known to the speaker and the hearer (Baker \& Greenfield, 1988; Bates, 1976). If children's "new-first" ordering pattern at the phrasal level is influenced by similar considerations, we would expect that they also select the new referent when they produce only one object label. When we examine the single noun phrases that children spontaneously produced when shown two objects in the warm-up or (the excluded responses in) the test trials, we find a strong child preference to label only the new object (42/51 cases). Such a selection preference is suggestive of what children consider worthy of mention, and may well play an important role in explaining the ordering biases we find in our study.

\section{Acknowledgements}

We gratefully acknowledge the cooperation of the children and adults who participated in our study at the following locations: Evangelische Kindertagesstätte, Kindergarten St. Johannes, Kinderhort (Allround Sports), Kernwasserwunderland (Freizeitpark), Campingplatz Diehr, and Campingplatz Dilborner Mühle in Germany, the German-speaking students of the Radboud University, Nijmegen, The Netherlands and the children who participated in the pilots: Julia, Olek, and Jakob Skiba and Melanie Dunn. We thank Tilman Harpe, Anika Borsch, Luzia Unverricht, Andrieke Thissen, and Janneke van Ekert for their invaluable assistance in 
data-collection and coding, and our colleagues who provided critical advice on aspects of the study: Harald Baayen, Melissa Bowerman, Bettina Braun, Aoju Chen, Laura Herbst, Elizabeth Johnson, Peter Jordens, Wolfgang Klein, Asifa Majid, Leah Roberts, and Sarah Schimke. Any remaining errors are solely ours. We are also grateful to the reviewers of this paper for their valuable feedback.

\section{References}

Akhtar, N., \& Tomasello, M. (1997). Young children's productivity with word order and verb morphology. Developmental Psychology, 33, 952-965.

Arnold, J. W., Wasow, T., Losongco, A., \& Grinstorm, R. (2000). Heaviness vs. newness: The effects of structural complexity and discourse status on constituent ordering. Language, 76, 28-55.

Baayen, H. (in press). Analyzing linguistic data: A practical introduction to statistics. Cambridge: Cambridge University Press.

Baker, N. D., \& Greenfield, P. M. (1988). The development of new and old information in young children's early language. Language Sciences, 10, 3-34.

Bates, E. (1976). Language and context: The acquisition of pragmatics. New York: Academic Press.

Bock, J. K. (1977). The effect of a pragmatic presupposition on syntactic structure in question answering. Journal of Verbal Learning and Verbal Behavior, 16, 723-734.

Bock, J. K., \& Irwin, D. E. (1980). Syntactic effects of information availability in sentence production. Journal of Verbal Learning and Verbal Behavior, 19, 467.

Bock, J. K., \& Warren, R. K. (1985). Conceptual accessibility and syntactic structure in sentence formulation. Cognition, 21, 47-67.

Braine, M. D. S. (1976). Children's first word combinations. Chicago: University of Chicago Press.

Clark, H. H., \& Chase, W. G. (1972). On the process of comparing sentences against pictures. Cognitive Psychology, 3, 472-517.

Clark, E. V., \& Clark, H. H. (1978). Universals, relativity, and language processing. In: J. H. Greenberg (Ed.), Universals of human language, Vol. I. (pp. 225-277). Stanford: Stanford University Press. (Reprinted from Psychology and Language by E. V. Clark, \& H. H. Clark, Harcourt Brace and Jovanovich (1977)).

Cooper, W. E., \& Ross, J. R. (1975). World Order. In R. E. Grossman, L. J. San, \& T. J. Vance (Eds.), Papers from the parasession on functionalism (pp. 63-111). Chicago Linguistic Society.

Ferreira, V. S., \& Yoshita, H. (2003). Given-new ordering effects on the production of scrambled sentences in Japanese. Journal of Psycholinguistic Research, 32, 669.

Fisher, C., \& Tokura, H. (1995). The given/new contract in speech to infants. Journal of Memory and Language, 34, 287-310.

Gleason, J. B., \& Weintraub, S. (1978). Input language and the acquisition of communicative competence. In K. E. Nelson (Ed.). Children's language (Vol. 1, pp. 171-222). New York: Gardiner Press.

Goldin-Meadow, S., \& Mylander, C. (1984). Gestural communication in deaf children: The effects and non-effects of parental input on early language development. Monographs of the Society for Research in Child Development, 49, 3-4, Serial No. 207.

Grimm, H., \& Doil, H. (2000). Elternfragebogen für die Früherkennung von Risikokindern. Göttingen: Hogrefe.

Hickmann, M., Hendriks, H., Roland, F., \& Liang, J. (1996). The marking of new information in children's narratives: A comparison of English, French, German, and Mandarin Chinese. Journal of Child Language, 23, 591-619.

Karmiloff-Smith, A. (1986). Some fundamental aspects of language development after age five. In P. Fletcher \& M. Garman (Eds.), Language acquisition: Studies in first language development (pp. 455-474). Cambridge: Cambridge University Press.

Kelly, M. H., Bock, J. K., \& Keil, F. C. (1986). Prototypicality in a linguistic context: Effects on sentences structure. Journal of Memory and Language, 25, 59-74. 
Levelt, W. J. M. (1989). Speaking: From intention to articulation. Cambridge, MA: MIT Press.

MacWhinney, B. (1982). Basis syntactic processes. In S. Kuczaj (Ed.), Language development (pp. 73-136). Hillsdale, NY: Lawrence Erlbaum Associates.

MacWhinney, B. (1985). Hungarian language acquisition as an exemplification of a general model of grammatical development. In D. Slobin (Ed.), The cross-cultural study of language acquisition. Hillsdale, NJ: Lawrence Erlbaum Associates.

MacWhinney, B., \& Bates, E. (1978). Sentential devices for conveying givenness and newness: A crosscultural development study. Journal of Verbal Learning and Verbal Behavior, 17, 539-558.

MacWhinney, B., \& Price, D. (1980). The development of the comprehension of topic-comment marking. In D. Ingram, C. C. Peng, \& P. Dale (Eds.), Proceedings of the first international congress for the study of child language. Lanham, MD: University Press of America.

Menyuk, P. (1969). Sentences children use. Cambridge: MIT Press.

O'Grady, W. D. (1997). Syntactic development. Chicago: University of Chicago Press.

Pinker, S., \& Birdsong, D. (1979). Speakers' sensitivity to rules of frozen word order. Journal of Verbal Learning and Verbal Behavior, 18, 497-508.

Prat-Sala, M., Shillcock, R., \& Sorace, A. (2000). Animacy effects on the production of objects dislocated descriptions by Catalan-speaking children. Journal of Child Language, 27, 97-117.

Reinhart, T. (1982). Pragmatics and linguistics: An analysis of sentence topics. Bloomington, IN: Indiana University Linguistics Club.

von Stutterheim, C., \& Klein, W. (2002). Quaestio and L-perspectivation. In C. F. Graumann \& W. Kallmeyer (Eds.), Perspective and perspectivation in discourse (pp. 59-88). Amsterdam: Benjamins.

Tomasello, M. (2003). Constructing a language. A usage-based theory of language acquisition. Cambridge, MA: Harvard University Press.

Wright, S. K., Hay, J., \& Bent, T. (2005). Ladies first? Phonology, frequency, and the naming conspiracy. Linguistics, 43, 531-561.

Wundt, W. M. (1900). Die Sprache. Leipzig: Engelmann.

Yule, G. (1997). Referential communication tasks. Mahwah, NY: Lawrence Erlbaum Associates. 